\title{
A Comparison of Real-World Treatment Patterns and Clinical Outcomes in Patients Receiving First-Line Therapy for Unresectable Advanced Gastric or Gastroesophageal Junction Cancer Versus Esophageal Adenocarcinomas
}

\author{
Veena Shankaran (D) Hong Xiao · David Bertwistle · Ying Zhang • \\ Min You · Pranav Abraham · Ian Chau \\ Received: August 9, 2020 / Accepted: November 10, 2020 / Published online: November 26, 2020 \\ (C) The Author(s) 2020
}

\section{ABSTRACT}

Introduction: Management of locally advanced, unresectable, or metastatic (adv/met) esophageal adenocarcinoma (EAC) follows clinical guidance for gastric cancer (GC) and gastroesophageal junction cancer (GEJC). However, evidence for these guidelines is based largely on patients with adv/met GC/GEJC, and generally excludes patients with EAC. It is currently unclear whether patients with adv/met GC/GEJC and adv/met EAC have similar demographics and clinical outcomes in realworld practice.

Methods: Adult patients diagnosed with adv/ met GC/GEJC and adv/met EAC between January 1, 2011 and November 30, 2018 were identified (Flatiron Health database); patients

V. Shankaran ( $\square)$

Division of Oncology, Department of Medicine, Seattle Cancer Care Alliance, Seattle, WA, USA

e-mail:vshank@uw.edu

H. Xiao · Y. Zhang · M. You · P. Abraham

Bristol Myers Squibb, Lawrenceville, NJ, USA

D. Bertwistle

Bristol Myers Squibb, Uxbridge, Middlesex, UK

I. Chau

Gastrointestinal and Lymphoma Unit, The Royal

Marsden Hospital, Sutton, Surrey, UK with confirmed human epidermal growth factor receptor 2 (HER2)-positive tumors were excluded, and index was date of adv/met diagnosis. Median overall survival (OS) from start of firstline therapy until death/censoring was estimated by the Kaplan-Meier method. Multivariable analysis (Cox proportional hazards) was conducted to identify factors associated with OS.

Results: In total, 3052 patients were identified $(\mathrm{adv} / \mathrm{met}$ GC/GEJC, $n=2083$; adv/met EAC, $n=969)$. Patients with EAC were more likely to be male, have a history of smoking, have a higher body weight and body mass index, and were less likely to be Hispanic/Latino or Medicaid enrollees than patients with GC/GEJC. A similar proportion of patients with adv/met GC/GEJC (75\%; $n=2326)$ and adv/met EAC $(77 \% ; n=1573)$ received first-line therapy. Fluoropyrimidine plus platinum combinations were the most frequent first-line regimen in both groups (36\%). Median OS was similar for patients with adv/met GC/GEJC and adv/met EAC (9.7 vs. 9.1 months, respectively; hazard ratio [95\% confidence interval] 0.96 [0.87-1.06]; $p=0.4320)$.

Conclusion: Despite minor differences in baseline demographics, clinical outcomes for patients with adv/met GC/GEJC and EAC are similar. This supports the inclusion of patients with adv/met EAC in clinical trials assessing $\mathrm{adv} / \mathrm{med}$ GC/GEJC. 
Keywords: Esophageal adenocarcinoma; Gastric cancer; Gastroesophageal junction cancer

\section{Key Summary Points}

Why carry out this study?

Clinical management of locally advanced, unresectable, or metastatic (adv/met) esophageal adenocarcinoma (EAC) generally follows the recommendations for adv/met gastric cancer (GC) and adv/ met gastroesophageal junction cancer (GEJC).

Few studies have assessed whether patients receiving first-line therapy for $\mathrm{adv} / \mathrm{met}$ GC/GEJC and adv/met EAC have similar demographics, treatment patterns, and clinical outcomes in routine clinical practice.

\section{What was learned from the study?}

In this real-world analysis of electronic health records, there were some minor underlying demographic differences between patients with adv/met GC/GEJC and adv/met EAC; patients with EAC were more likely to be male, have a history of smoking, have a higher body weight and body mass index, and were less likely to be Hispanic/Latino or Medicaid enrollees.

Both groups of patients appeared to receive comparable treatment in realworld practice, with fluoropyrimidine plus platinum combinations the most frequent first-line regimen in both groups; over one-third of patients in each group (36\%) received these agents.

Median OS was broadly similar for those who were diagnosed with adv/met GC/ GEJC (9.7 months) and those with adv/ met EAC (9.1 months); Cox regression indicated that survival was not associated with the primary site of disease (GC/GEJC vs. EAC).
Time to next treatment and progressionfree survival were also similar between patients with adv/met GC/GEJC and those with adv/met EAC.

In real-world clinical practice, patients with EAC are treated similarly to those with adv/met GC/GEJC, and have similar outcomes; patients with adv/met EAC should therefore be included in clinical trials of adv/met GC/GEJC.

\section{DIGITAL FEATURES}

This article is published with digital features, including a summary slide, to facilitate understanding of the article. To view digital features for this article go to https://doi.org/10.6084/ m9.figshare.13208183.

\section{INTRODUCTION}

Gastric and esophageal cancers are among the most frequent cause of cancer-related deaths worldwide [1]. In the USA, it is estimated that gastric cancer (GC) and esophageal cancer will account for 11,140 and 16,080 deaths in 2019, respectively, according to mortality data from the National Center for Health Statistics [2]. GC (including gastroesophageal junction cancers) and esophageal cancers often remain undiagnosed until a relatively late stage in the disease course, and 5-year survival in patients with distant metastatic disease is approximately 5\% $[2,3]$. Esophageal adenocarcinoma (EAC) is the most common esophageal cancer subtype in the USA, accounting for approximately $60 \%$ of US esophageal cancer cases [4].

For locally advanced, unresectable, or metastatic (adv/met) GC/GEJC, National Comprehensive Cancer Network Guidelines ${ }^{\circledR}$ recommend first-line treatment with fluoropyrimidine-based (fluorouracil or capecitabine) and platinum-based (cisplatin or oxaliplatin) combinations, with the addition of trastuzumab for patients who have human epidermal growth factor receptor 2 (HER2)-positive tumors. 
Clinical management of EAC typically follows the recommendations for GC/GEJC $[5,6]$. However, much of the evidence for first-line therapy in this clinical setting is based on trials of patients with adv/met GC and/or GEJC [7-10] or esophageal squamous cell carcinoma [11], and patients with EAC have generally been excluded from these trials. In fact, of the evidence base cited by these guidelines to support first-line therapy of EAC, only one study explicitly included patients with EAC [12]. Recent genomic analyses have shown that the molecular characteristics of EAC are more similar to gastric adenocarcinomas than to esophageal squamous cancer [13], but it remains unclear whether patients with adv/met GC/ GEJC and adv/met EAC have similar demographics and clinical outcomes in routine clinical practice, which may provide insight into the validity of enrolling patients with adv/met EAC in adv/met GC/GEJC clinical trials. This study aimed to compare real-world demographics, treatment patterns, and clinical outcomes of patients with adv/met GC/GEJC and $\mathrm{adv} / \mathrm{met} \mathrm{EAC}$.

\section{METHODS}

\section{Data Source and Patient Selection}

This article is based on observational data from the Flatiron Health electronic health record database, and does not contain any studies with human participants or animals performed by any of the authors.

This retrospective observational study used Flatiron Health's longitudinal demographically and geographically diverse database, which contains electronic health record data from more than 280 cancer clinics including over 2.4 million US patients with active cancer [14]. The Flatiron database de-identified, patient-level unstructured data collected via technology-enabled chart abstraction from physician notes and other documents, in addition to structured data. Structured data include demographics, diagnosis codes (International Classification of Diseases, 9th and 10th Revisions), laboratory visits, medications, and Eastern Cooperative
Oncology Group (ECOG) performance status (PS). Unstructured data include date of initial diagnosis, stage at initial diagnosis, primary tumor characteristics, biomarker testing, and limited information on surgeries.

Patients with a record of adv/met GC/GEJC/ EAC in routine clinical practice from January 1 , 2011 through November 30, 2018 were included; index date was the date of adv/met diagnosis. Patients were eligible for this study if they were at least 18 years of age, had a diagnosis of $\mathrm{adv} / \mathrm{met}$ gastric/gastroesophageal/esophageal cancer, had histologically confirmed adenocarcinoma, and had at least 1 month of available medical data after index; eligibility criteria and patient attrition are presented in Fig. 1. Patients with evidence of HER2-positive cancer (either by a positive test for HER2 expression or as indicated by receipt of trastuzumab) were excluded from the analysis, given that these patients generally receive HER2-targeted therapies and have different clinical outcomes compared with patients with non-HER2-positive GC/GEJC [15]. Patients were followed up until death, discontinuation from database, or the end of the study period, whichever came earlier. The start of the first-line therapy was defined as the initiation date of the first eligible therapy recorded after or up to 14 days before the index date. The end of first-line therapy was defined as the date of last recorded administration of firstline therapy (or by death or censoring, as appropriate). Advancement to second-line therapy was defined as receipt of an entirely new therapy regimen or a gap in therapy of more than 120 days.

Cisplatin/carboplatin substitution was considered not to indicate a change in line of therapy, as was substitution between fluorouracil/capecitabine, substitution or addition of leucovorin or levoleucovorin, and addition of ramucirumab, to chemotherapy/targeted therapy.

\section{Study Variables and Outcomes}

For all patients who met inclusion criteria, baseline variables were recorded, including age, sex, race, disease stage at initial diagnosis, 

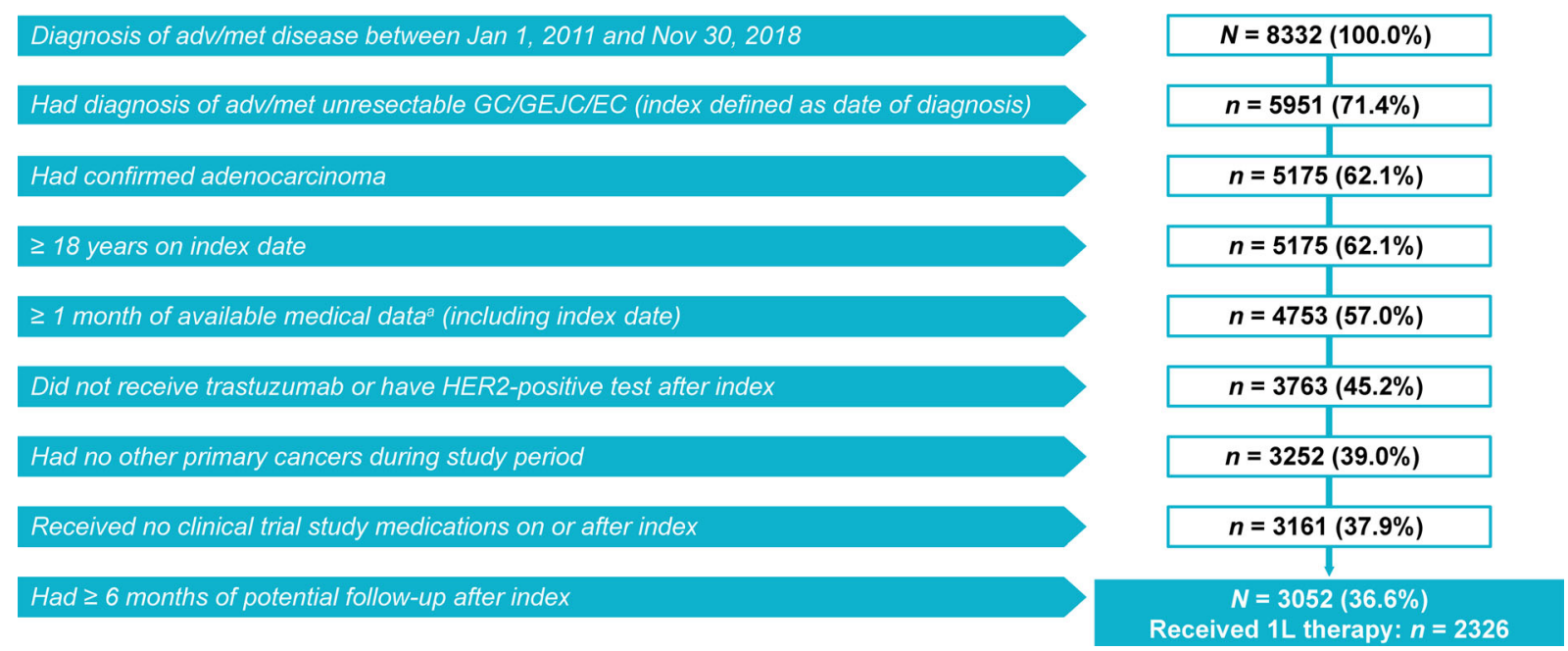

Fig. 1 Patient identification and attrition. $I L$ first-line, $a d v / m e t$ advanced/metastatic, $E A C$ esophageal adenocarcinoma, GC gastric cancer, GEJC gastroesophageal junction cancer, HER2 human epidermal growth factor receptor 2. Resection status (resectable/unresectable)

ECOG PS, and primary tumor location. Treatment patterns and clinical outcomes were assessed in patients who subsequently received active therapy. Individual first-line treatment regimens received were identified and summarized. Overall survival (OS) was defined as the time from start of first-line therapy until date of death or censoring (last recorded medical activity). Duration of first-line therapy was defined as the time from start of first-line therapy until the last record of first-line therapy. Real-world progression (a proxy for progressionfree survival as recorded in clinical trials) was defined as the time from start of first-line treatment until disease progression, death, or censoring. Time to next treatment (TTNT) was defined as the time from start of first-line therapy until start of second-line therapy (or until death or censoring, if the patients did not receive second-line therapy).

\section{Statistical Analyses}

Baseline demographics and patient characteristics at the index date were summarized using descriptive statistics; frequencies and proportions were reported for categorical data, and derived from chart abstraction. ${ }^{\mathrm{a}}$ Medical data were defined as clinical data in the patient record from outpatient physician office visits, nonfacility visits, laboratory visits, treatment/procedure visits, or medication administration; patients who died within 1 month were not excluded

means (standard deviations) and medians (ranges) were provided for continuous data. Median (95\% confidence intervals, CIs) for OS, realworld progression, and TTNT were estimated by the Kaplan-Meier method. A multivariable analysis (Cox proportional hazards model) was conducted to identify factors associated with OS in patients receiving first-line therapy.

\section{RESULTS}

\section{Baseline Demographics and Disease Characteristics}

After inclusion/exclusion criteria were applied, 3052 patients diagnosed with adv/met GC/ GEJC/EAC were identified (adv/met GC/GEJC, $n=2083$; adv/met EAC, $n=969$ ) (Fig. 1). Baseline demographics and disease characteristics at index for all included patients are shown in Table 1 ; the median age of included patients was 66 years; $74 \%$ were male, $63 \%$ were white, $61 \%$ had a history of smoking, and $64 \%$ had been diagnosed with stage IV disease at initial diagnosis. The primary site of disease was GC/ GEJC in $68 \%$ of patients and EAC in $32 \%$ of patients. When stratified by primary site of 
Table 1 Baseline patient demographics and disease characteristics in patients diagnosed with adv/met GC/GEJC and $\mathrm{adv} / \mathrm{met}$ EAC

\begin{tabular}{|c|c|c|c|c|}
\hline & $\begin{array}{l}\text { All } \\
(n=3052)\end{array}$ & $\begin{array}{l}\text { Adv/met GC/GEJC } \\
(n=2083)\end{array}$ & $\begin{array}{l}\text { Adv/met EAC } \\
(n=969)\end{array}$ & $p$ value \\
\hline Median (range) age at index, years & $66(24-85)$ & $66(25-85)$ & $66(24-85)$ & 0.2900 \\
\hline Age group at index, $n(\%)$ & & & & 0.4564 \\
\hline$\geq 65$ years & $1655(54.2)$ & $1120(53.8)$ & $535(55.2)$ & \\
\hline$<65$ years & $1397(45.8)$ & $963(46.2)$ & $434(44.8)$ & \\
\hline Sex, $n(\%)$ & & & & $<0.0001$ \\
\hline Male & $2263(74.1)$ & $1393(66.9)$ & $870(89.8)$ & \\
\hline Female & $789(25.9)$ & $690(33.1)$ & $99(10.2)$ & \\
\hline Practice type, $n(\%)$ & & & & 0.5313 \\
\hline Community & $2909(95.3)$ & $1982(95.2)$ & $927(95.7)$ & \\
\hline Academic & $143(4.7)$ & $101(4.8)$ & $42(4.3)$ & \\
\hline \multicolumn{5}{|l|}{ Benefit plan type, $n(\%)$} \\
\hline Commercial health plan & $1072(35.1)$ & $728(34.9)$ & $344(35.5)$ & 0.7666 \\
\hline Medicare & $719(23.6)$ & $498(23.9)$ & $221(22.8)$ & 0.5047 \\
\hline Medicaid & $99(3.2)$ & $78(3.7)$ & $21(2.2)$ & 0.022 \\
\hline Other government program & $96(3.1)$ & $65(3.1)$ & $31(3.2)$ & 0.9077 \\
\hline Patient assistance program & $30(1.0)$ & $21(1.0)$ & $9(0.9)$ & 0.8361 \\
\hline Self-pay & $13(0.4)$ & $11(0.5)$ & $2(0.2)$ & 0.204 \\
\hline Other & $563(18.4)$ & $390(18.7)$ & $173(17.9)$ & 0.5643 \\
\hline Missing & $976(32.0)$ & $649(31.2)$ & $327(33.7)$ & 0.1534 \\
\hline Geographic region, $n(\%)$ & & & & $<0.0001$ \\
\hline South & $1094(35.8)$ & $778(37.3)$ & $316(32.6)$ & \\
\hline Northeast & $639(20.9)$ & $414(19.9)$ & $225(23.2)$ & \\
\hline West & $642(21.0)$ & $458(22.0)$ & $184(19.0)$ & \\
\hline Midwest & $453(14.8)$ & $261(12.5)$ & $192(19.8)$ & \\
\hline Other & $55(1.8)$ & $47(2.3)$ & $8(0.8)$ & \\
\hline Missing & $169(5.5)$ & $125(6.0)$ & $44(4.5)$ & \\
\hline Race, $n(\%)$ & & & & $<0.0001$ \\
\hline White & $1913(62.7)$ & $1177(56.5)$ & $736(76.0)$ & \\
\hline Black or African American & $208(6.8)$ & $181(8.7)$ & $27(2.8)$ & \\
\hline Asian & $138(4.5)$ & $129(6.2)$ & $9(0.9)$ & \\
\hline Other & $423(13.9)$ & $335(16.1)$ & $88(9.1)$ & \\
\hline
\end{tabular}


Table 1 continued

\begin{tabular}{|c|c|c|c|c|}
\hline & $\begin{array}{l}\text { All } \\
(n=3052)\end{array}$ & $\begin{array}{l}\text { Adv/met GC/GEJC } \\
(n=2083)\end{array}$ & $\begin{array}{l}\text { Adv/met EAC } \\
(n=969)\end{array}$ & $p$ value \\
\hline Missing & $370(12.1)$ & $261(12.5)$ & $109(11.2)$ & \\
\hline Ethnicity, $n(\%)$ & & & & $<0.0001$ \\
\hline Hispanic or Latino & $313(10.3)$ & $275(13.2)$ & $38(3.9)$ & \\
\hline Other/missing & $2739(89.7)$ & $1808(86.8)$ & $931(96.1)$ & \\
\hline Smoking status, $n$ (\%) & & & & $<0.0001$ \\
\hline History of smoking & $1871(61.3)$ & $1162(55.8)$ & $709(73.2)$ & \\
\hline No history of smoking & $1082(35.5)$ & $849(40.8)$ & $233(24.0)$ & \\
\hline Missing & $99(3.2)$ & $72(3.5)$ & $27(2.8)$ & \\
\hline Weight at index, $\mathrm{lb}$ & $n=2258$ & $n=1501$ & $n=757$ & $<0.0001$ \\
\hline Mean (SD) & $173.9(45.3)$ & $167.6(44.3)$ & $186.2(44.7)$ & \\
\hline Median (range) & $169(68.6-385.4)$ & $162(68.6-385.4)$ & $182(84.0-380.0)$ & \\
\hline BMI at index, $\mathrm{kg} / \mathrm{m}^{2}$ & $n=2247$ & $n=1493$ & $n=754$ & $<0.0001$ \\
\hline Mean (SD) & $26.7(6.1)$ & $26.2(5.8)$ & $27.9(6.5)$ & \\
\hline Median (range) & $26.2(12.2-67.3)$ & $25.6(12.2-51.2)$ & $27.2(14.4-67.3)$ & \\
\hline Median (range) follow-up from index, mo & $7.8(0.1-95.1)$ & $7.9(0.2-95.1)$ & $7.7(0.1-80.9)$ & 0.6105 \\
\hline Stage at initial diagnosis, $n(\%)$ & & & & 0.9345 \\
\hline Stage I-III & $835(27.4)$ & $573(27.5)$ & $262(27.0)$ & \\
\hline Stage IV & $1967(64.4)$ & $1338(64.2)$ & $629(64.9)$ & \\
\hline Missing & $250(8.2)$ & $172(8.3)$ & $78(8.0)$ & \\
\hline ECOG PS at start of $1 \mathrm{~L}, n(\%)$ & & & & 0.1969 \\
\hline Not available & $1123(48.3)$ & $774(49.2)$ & $349(46.3)$ & \\
\hline Available & $1203(51.7)$ & $799(50.8)$ & $404(53.7)$ & 0.7225 \\
\hline $0-1$ & $1003(83.4)$ & $664(83.1)$ & $339(83.9)$ & \\
\hline$\geq 2$ & $200(16.6)$ & $135(16.9)$ & $65(16.1)$ & \\
\hline
\end{tabular}

$I L$ first-line, adv/met locally advanced, unresectable, or metastatic, $B M I$ body mass index, $E A C$ esophageal adenocarcinoma, ECOG PS Eastern Cooperative Oncology Group performance status, $G C$ gastric cancer, GEJC gastroesophageal junction cancer, $S D$ standard deviation 
disease (GC/GEJC vs. EAC), patients with EAC were more likely to be male $(67 \%$ vs. $90 \%$; $p<0.0001$ ), have a history of smoking (56\% vs. $73 \% ; p<0.0001$ ), have a higher baseline body weight (mean $168 \mathrm{lbs}$ vs. $186 \mathrm{lbs} ; p<0.0001$ ), have a higher body mass index (mean $26.2 \mathrm{~kg} / \mathrm{m}^{2} \quad$ vs. $\left.\quad 27.9 \mathrm{~kg} / \mathrm{m}^{2} ; \quad p<0.0001\right)$ (Table 1).

\section{Treatment Patterns}

Among all patients diagnosed with adv/met GC/GEJC/EAC $\quad(n=3052), \quad 76 \% \quad(n=2326)$ received first-line therapy; the median time from diagnosis of advanced disease until start of first-line in these patients was identical in patients with adv/met GC/GEJC and in patients with adv/met EAC (1.1 months; Table 2). Among patients initiating first-line therapy for $\mathrm{adv} / \mathrm{met} \quad \mathrm{GC} / \mathrm{GEJC} / \mathrm{EAC} \quad(n=2326), \quad 36 \%$ received fluoropyrimidine plus platinum-based therapy (adv/met GC/GEJC, 36\%; adv/met EAC, $35 \%)$. Additionally, $11 \%$ of patients initiating first-line therapy for adv/met GC/GEJC/EAC received docetaxel in combination with fluoropyrimidine plus platinum-based therapy (adv/met GC/GEJC, 12\%; adv/met EAC, 11\%) and $12 \%$ received epirubicin in combination with fluoropyrimidine plus platinum-based therapy (adv/met GC/GEJC, 14\%; adv/met EAC, $8 \%)$. An additional $20 \%$ of patients initiating first-line therapy for adv/met GC/GEJC/EAC received taxanes plus platinum-based agents (adv/met GC/GEJC, 15\%; adv/met EAC, 30\%).

\section{Clinical Outcomes}

In patients who received first-line therapy for adv/met GC/GEJC/EAC, median OS was 9.5 months (Table 3 ), and was similar for those who were diagnosed with adv/met GC/GEJC and adv/met EAC (9.7 months vs. 9.1 months; Fig. 2). As the proportional hazards assumption was found not to hold for some variables, a time interaction term was added to extend the model to account for nonproportional hazards. Multivariable Cox regression of covariates indicated that the primary site of disease (GC/GEJC vs. EAC) was not associated with survival (hazard ratio [HR] [95\% CI] 0.96 [0.87-1.06]; $p=0.4320$ ) (Table 4). Disease stage at initial diagnosis (stage I-III vs. stage IV, HR $[95 \%$ CI] 0.64 [0.54-0.75]; $p<0.0001)$ and ECOG PS at start of first-line $\left(2-4\right.$ vs. $0-1$, HR $\left[\begin{array}{lll}95 \% & \text { CI }] & 2.63\end{array}\right.$ [2.01-3.45]; $p<0.0001)$ were significantly associated with survival in multivariable Cox regression. The probability of survival in patients who received first-line therapy for adv/ met GC/GEJC/EAC was $39 \%$ at 12 months and $15 \%$ at 24 months after start of first-line treatment (Table 3). Survival probability was similar between adv/met GC/GEJC and adv/met EAC at 12 months (40\% vs. $36 \%$, respectively) and 24 months (15\% vs. $13 \%$, respectively) (Fig. 2; Table 3). Median (95\% CI) TTNT in all patients who received first-line therapy was 5.3 (5.1-5.6) months, and was similar between adv/met GC/ GEJC and adv/met EAC subgroups (5.4 [5.1-5.7] months and 5.1 [4.7-5.6] months, respectively). Median (95\% CI) real-world progression in all patients who received first-line therapy was 5.1 (4.9-5.4) months, and was similar between adv/ met GC/GEJC and adv/met EAC subgroups (5.3 [5.0-5.6] months and 4.8 [4.4-5.3] months, respectively).

\section{DISCUSSION}

This study provides important data directly comparing baseline demographic and clinical characteristics and treatment patterns and is the first to directly compare survival in US patients receiving first-line therapy for adv/met GC/ GEJC versus adv/met EAC in routine clinical practice. We identified statistically significant differences in baseline characteristics between patients with adv/met GC/GEJC and patients with adv/met EAC that reflect underlying differences in disease epidemiology. The observed predominance of male patients with EAC (90\%) is similar to that previously reported in North America [16]. Similarly, EAC has been reported to occur more frequently in white patients than in patients of other races [17]. Obesity has been previously demonstrated to be a risk factor for EAC and GEJC $[1,18]$; in the present analysis, baseline body mass index was higher in patients diagnosed with EAC than with GC/GEJC. The 
Table 2 Treatment patterns in patient diagnosed with adv/met GC/GEJC and adv/met EAC

\begin{tabular}{|c|c|c|c|}
\hline & All $(n=3052)$ & $\begin{array}{l}\text { Adv/met GC/GEJC } \\
(n=2083)\end{array}$ & $\begin{array}{l}\text { Adv/met EAC } \\
(n=969)\end{array}$ \\
\hline Received 1L therapy, $n(\%)$ & $2326(76.2)$ & $1573(75.5)$ & $753(77.7)$ \\
\hline $\begin{array}{l}\text { Median (range) time from index to } 1 \mathrm{~L} \text {, } \\
\text { months }\end{array}$ & $1.1(0-89.9)$ & $1.1(0-89.9)$ & $1.1(0-63.0)$ \\
\hline Median (range) duration of $1 \mathrm{~L}$, months & $2.1(0.03-34.2)$ & $2.3(0.03-34.2)$ & $1.9(0.03-25.1)$ \\
\hline \multicolumn{4}{|l|}{ Regimen classes in $1 \mathrm{~L}, n(\%)$} \\
\hline Fluoropyrimidine + platinum & $828(35.6)$ & $568(36.1)$ & $260(34.5)$ \\
\hline Taxane plus platinum & $454(19.5)$ & $229(14.6)$ & $225(29.9)$ \\
\hline $\mathrm{ECF}^{\mathrm{a}}$ & $276(11.9)$ & $215(13.7)$ & $61(8.1)$ \\
\hline $\mathrm{DCF}^{\mathrm{a}}$ & $263(11.3)$ & $183(11.6)$ & $80(10.6)$ \\
\hline Fluoropyrimidine monotherapy & $201(8.6)$ & $167(10.6)$ & $34(4.5)$ \\
\hline Fluorouracil + irinotecan + leucovorin & $42(1.8)$ & $30(1.9)$ & $12(1.6)$ \\
\hline Taxane monotherapy & $37(1.6)$ & $19(1.2)$ & $18(2.4)$ \\
\hline Other & $225(9.7)$ & $162(10.3)$ & $63(8.4)$ \\
\hline
\end{tabular}

Regimen classes are not mutually exclusive categories; percentages are calculated relative to number of patients receiving $1 \mathrm{~L}$ $1 L$ first-line, adv/met locally advanced, unresectable, or metastatic, DCF docetaxel plus cisplatin and fluorouracil, EAC esophageal adenocarcinoma, $E C F$ epirubicin plus cisplatin and fluorouracil, $G C$ gastric cancer, $G E J C$ gastroesophageal junction cancer

a Includes "modified" DCF/ECF (i.e., could include any fluoropyrimidine or platinum-based therapy, in combination with docetaxel/epirubicin)

underlying differences in baseline demographics presented here may reflect the risk factors for GC/GEJC and EAC; regardless, the treatment and outcomes in these patients once diagnosed are broadly comparable. Recently, another publication using the Flatiron database reported demographics for patients with advanced GC, advanced GEJC, and advanced EAC [19]. As expected, despite minor differences in inclusion criteria, baseline demographics were very similar to those seen in the present analysis.

Clinical guidelines suggest that patients initiating first-line therapy for adv/met GC/GEJC/ EAC should receive fluoropyrimidine plus platinum-based therapy [6]. The majority of patients (almost 60\%) in this analysis received first-line fluoropyrimidine plus platinum-based therapy, with or without additional agents (such as docetaxel and epirubicin). Findings from the study reported by Barzi et al. support our observations that patients with adv/met EAC are treated similarly to patients with adv/ met GC/GEJC [19]. However, we did observe that first-line taxane plus platinum-based therapy appeared to be lower in patients with adv/ met GC/GEJC than with adv/met EAC.

Clinical outcomes in real-world patients with adv/met GC/GEJC and adv/met EAC appeared similar in this analysis, with comparable median OS and survival rates at 1 and 2 years after initiating first-line therapy. These observations are broadly in line with a pooled analysis of clinical trial patients with adv/met GC/GEJC and adv/met EAC, which reported comparable survival outcomes for these populations receiving first-line fluoropyrimidines with or without platinum-based chemotherapies; the OS values reported in that analysis were strikingly similar to those in the present study (adv/met GC, 8.7 months; GEJC, 
Table 3 Clinical outcomes in patients diagnosed with adv/met GC/GEJC and adv/met EAC

\begin{tabular}{lccc}
\hline & $\begin{array}{l}\text { All } \\
(\boldsymbol{n}=\mathbf{2 3 2 6})\end{array}$ & $\begin{array}{l}\text { Adv/met GC/GEJC } \\
(\boldsymbol{n}=\mathbf{1 5 7 3})\end{array}$ & $\begin{array}{l}\text { Adv/met EAC } \\
(\boldsymbol{n}=\mathbf{7 5 3})\end{array}$ \\
\hline Median (95\% CI) OS from start of 1L, months & $9.5(9.0-9.9)$ & $9.7(9.0-10.2)$ & $9.1(8.4-9.9)$ \\
Survival probability at 12 months (SD) & $38.8(1.1)$ & $40.4(1.3)$ & $35.7(1.9)$ \\
Survival probability at 24 months (SD) & $14.8(0.9)$ & $15.5(1.1)$ & $13.3(1.5)$ \\
Median (95\% CI) TTNT from start of 1L, months & $5.3(5.1-5.6)$ & $5.4(5.1-5.7)$ & $5.1(4.7-5.6)$ \\
$\begin{array}{l}\text { Median (95\% CI) real-world progression from start of } \\
\text { 1L, months }\end{array}$ & $5.1(4.9-5.4)$ & $5.3(5.0-5.6)$ & $4.8(4.4-5.3)$ \\
\hline
\end{tabular}

$I L$ first-line, adv/met locally advanced, unresectable, or metastatic, $C I$ confidence interval, $E A C$ esophageal adenocarcinoma, $G C$ gastric cancer, GEJC gastroesophageal junction cancer, $O S$ overall survival, $S D$ standard deviation, TTNT time to next treatment

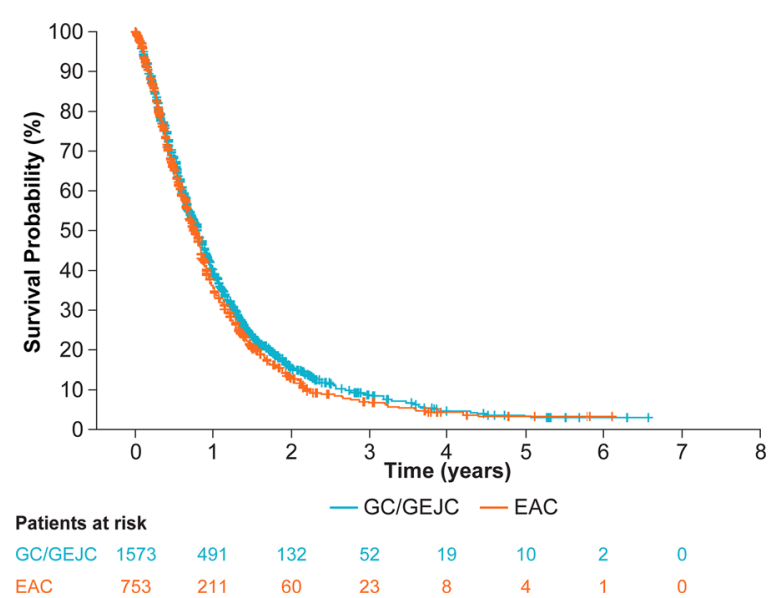

Fig. 2 Survival outcomes from start of $1 \mathrm{~L}$ in patients with $\mathrm{adv} / \mathrm{met} \mathrm{GC} / \mathrm{GEJC}$ and adv/met EAC. $1 L$ first-line, adv/ met locally advanced, unresectable, or metastatic, $C I$ confidence interval, $E A C$ esophageal adenocarcinoma, $G C$ gastric cancer, $G E J C$ gastroesophageal junction cancer, $O S$ overall survival, $S D$ standard deviation. All patients in survival analysis had at least 6 months of potential followup

9.3 months; adv/met EAC, 9.5 months) [20]. Despite available treatment options, prognosis for patients with adv/met GC/GEJC/EAC remains poor; median OS in recent trials of firstline chemotherapy for advanced GC was 8.8-14.1 months [21-24].

Although EAC and GC have been shown to be molecularly similar [13], underlying molecular and biomarker differences between EAC and GC/GEJC may remain. We excluded patients with confirmed HER2 status; HER2 testing is recommended for all patients with $\mathrm{adv} / \mathrm{met} \mathrm{EAC} / \mathrm{GC} / \mathrm{GEJC}$, and such patients typically received different therapy (HER2-targeted therapies in addition to the chemotherapy backbone received by non-HER2-positive patients), which is associated with superior clinical outcomes [15]. Expression of other biomarkers, including microsatellite instabilityhigh or deficient mismatch repair, programmed death 1/programmed death ligand 1, and Epstein-Barr virus, may differ between EAC, GC, and GEJC, but as these biomarkers were not routinely tested for in clinical practice during the study observation period (2011-2018), we were unable to consider their impact in the current study. However, future studies may wish to evaluate the relative prevalence of these biomarkers in EAC, GC, and GEJC.

This is the first study to compare the demographics and clinical outcomes of real-world US patients with adv/met GC/GEJC and adv/met EAC receiving first-line therapy, and uses the Flatiron Health electronic health record database. The Flatiron database has been shown to be nationally representative of the US community oncology setting, and patient demographics are generally similar to those of the Surveillance, Epidemiology and End Results program [25]. Several limitations common to all real-world analyses are present, such as the lack 
Table 4 Multivariable Cox regression HRs (including time interaction terms) for survival from start of 1L

\begin{tabular}{|c|c|c|c|}
\hline Comparator & Reference & HR (95\% CI) & $p$ value \\
\hline \multicolumn{4}{|l|}{ Primary site of disease } \\
\hline GC/GEJC & EAC & $0.96(0.87-1.06)$ & 0.4320 \\
\hline \multicolumn{4}{|l|}{ Age group } \\
\hline$\geq 65$ years & $<65$ years & $1.04(0.93-1.16)$ & 0.5151 \\
\hline \multicolumn{4}{|l|}{ Practice type } \\
\hline Academic & Community & $2.31(0.43-12.47)$ & 0.3306 \\
\hline \multicolumn{4}{|l|}{ Sex } \\
\hline Male & Female & $1.10(0.98-1.23)$ & 0.1175 \\
\hline \multicolumn{4}{|l|}{ Race } \\
\hline Asian & White & $0.82(0.64-1.05)$ & 0.1203 \\
\hline Black & & $1.01(0.84-1.22)$ & 0.9119 \\
\hline Other & & $0.77(0.66-0.90)$ & 0.0008 \\
\hline Missing & & $1.43(1.22-1.68)$ & $<0.0001$ \\
\hline \multicolumn{4}{|l|}{ US region } \\
\hline Midwest & South & $0.97(0.78-1.20)$ & 0.7829 \\
\hline Northeast & & $0.79(0.65-0.96)$ & 0.0163 \\
\hline West & & $0.83(0.68-1.01)$ & 0.0612 \\
\hline Other & & $0.41(0.18-0.92)$ & 0.0294 \\
\hline Missing & & $0.64(0.12-3.30)$ & 0.5909 \\
\hline \multicolumn{4}{|l|}{ Insurance type } \\
\hline Multiple types & Commercial plan & $1.03(0.87-1.21)$ & 0.7323 \\
\hline Medicare & & $0.91(0.74-1.11)$ & 0.3465 \\
\hline Medicaid & & $1.03(0.72-1.48)$ & 0.8549 \\
\hline Other & & $1.06(0.91-1.24)$ & 0.4334 \\
\hline Missing & & $0.98(0.86-1.11)$ & 0.7404 \\
\hline \multicolumn{4}{|c|}{ Disease stage at initial diagnosis } \\
\hline Stage I-III & Stage IV & $0.64(0.54-0.75)$ & $<0.0001$ \\
\hline Unknown & & $0.67(0.51-0.89)$ & 0.0053 \\
\hline \multicolumn{4}{|l|}{ Smoking status } \\
\hline History of smoking & No history of smoking & $0.98(0.83-1.14)$ & 0.7513 \\
\hline Unknown & & $1.39(0.93-2.07)$ & 0.1129 \\
\hline
\end{tabular}


Table 4 continued

\begin{tabular}{|c|c|c|c|}
\hline Comparator & Reference & HR (95\% CI) & $p$ value \\
\hline \multicolumn{4}{|c|}{ ECOG PS at start of $1 \mathrm{~L}$} \\
\hline ECOG PS 2-4 & ECOG PS $0-1$ & $2.63(2.01-3.45)$ & $<0.0001$ \\
\hline Missing & & $1.29(1.10-1.51)$ & 0.0013 \\
\hline \multicolumn{4}{|l|}{ Practice type $\times$ time } \\
\hline Academic & Community & $0.99(0.99-1.00)$ & 0.1044 \\
\hline \multicolumn{4}{|l|}{ US region $\times$ time } \\
\hline Midwest & South & $1.00(1.00-1.00)$ & 0.8082 \\
\hline Northeast & & $1.00(1.00-1.00)$ & 0.0577 \\
\hline West & & $1.00(1.00-1.00)$ & 0.0647 \\
\hline Other & & $1.00(1.00-1.00)$ & 0.8856 \\
\hline Missing & & $1.01(1.00-1.01)$ & 0.1507 \\
\hline \multicolumn{4}{|c|}{ Disease stage at initial diagnosis $\times$ time } \\
\hline Stage I-III & Stage IV & $1.00(1.00-1.00)$ & 0.4347 \\
\hline Unknown & & $1.00(1.00-1.00)$ & 0.0284 \\
\hline \multicolumn{4}{|l|}{ Smoking status $\times$ time } \\
\hline History of smoking & No history of smoking & $1.00(1.00-1.00)$ & 0.9752 \\
\hline Unknown & & $1.00(1.00-1.00)$ & 0.0872 \\
\hline \multicolumn{4}{|c|}{ ECOG PS at start of $1 \mathrm{~L} \times$ time } \\
\hline $2-4$ & $0-1$ & $1.00(1.00-1.00)$ & 0.0017 \\
\hline Missing & & $1.00(1.00-1.00)$ & 0.0032 \\
\hline
\end{tabular}

$I L$ first-line, $C I$ confidence interval, EAC esophageal adenocarcinoma, ECOG PS Eastern Cooperative Oncology Group performance status, $G C$ gastric cancer, GEJC gastroesophageal junction cancer, $H R$ hazard ratio

of clinical detail in the electronic health records and missing and/or miscategorized data. This analysis is reliant on accurate diagnosis of primary tumor site by the treating physician, and we were unable to objectively verify the recorded site of disease. Patient's medical history may not be complete if treatment was previously received at a nonparticipating center and/ or as an inpatient. Limitations in comparing survival estimates between clinical trial data and real-world analyses should be taken into consideration because of the potentially higher proportion of patients lost to follow-up in database analyses. Additionally, Flatiron holds no information on tumor mutational burden and microsatellite instability, which are known prognostic indicators in multiple solid tumors $[26,27]$. Future analyses may address this by incorporating comprehensive molecular/genomic tests such as FoundationOne. However, real-world data can provide important insights into routine clinical practice and real-world patient care [28]. 
Despite the molecular similarities of tumors in patients with GC/GEJC and EAC, suggesting that these cancers could be considered a single disease entity [13], many relevant clinical trials continue to exclude patients with EAC tumors. In the adv/met setting, future clinical trials should expand enrollment to patients with EAC.

\section{CONCLUSIONS}

Our analysis demonstrated that although there are some underlying differences between the demographics of patients with adv/met EAC and patients with adv/met GC/GEJC, clinical outcomes with first-line systemic therapy appear similar for these two populations. This supports inclusion of patients with $\mathrm{adv} / \mathrm{met}$ EAC in clinical trials of adv/met GC/GEJC.

\section{ACKNOWLEDGEMENTS}

Funding. Sponsorship for this study and the Journal's Rapid Service and Open Access fees were funded by Bristol Myers Squibb.

Authorship. All named authors meet the International Committee of Medical Journal Editors (ICMJE) criteria for authorship for this article, take responsibility for the integrity of the work as a whole, and have given their approval for this version to be published.

Medical Writing and Editorial Assistance. Writing and editorial assistance was provided by Martin Bell, PhD, of Envision Pharma Group, funded by Bristol Myers Squibb.

Disclosures. Veena Shankaran has received research funding from Astellas, AstraZeneca, Bristol Myers Squibb, and Merck. Ian Chau has held consulting or advisory roles with AstraZeneca, Bayer, Boehringer Ingelheim, Bristol Myers Squibb, Eli Lilly, Five Prime Therapeutics, Merck Serono, MSD, Oncologie International, Pierre Fabre, Roche/Genentech, and has received honoraria or research funding from Eli
Lilly, Janssen-Gilag, Merck-Serono, and Sanofi. Pranav Abraham, David Bertwistle, Hong Xiao, Ying Zhang, and Min You are employees of, and hold stock in, Bristol Myers Squibb.

Compliance with Ethics Guidelines. This article is based on observational data from the Flatiron Health electronic health record database, and does not contain any studies with human participants or animals performed by any of the authors.

Data Availability. The datasets generated during and/or analyzed during the current study are available from the corresponding author on reasonable request. Bristol Myers Squibb's policy on data sharing may be found at https://www.bms.com/researchers-andpartners/independent-research/data-sharingrequest-process.html.

Open Access. This article is licensed under a Creative Commons Attribution-NonCommercial 4.0 International License, which permits any non-commercial use, sharing, adaptation, distribution and reproduction in any medium or format, as long as you give appropriate credit to the original author(s) and the source, provide a link to the Creative Commons licence, and indicate if changes were made. The images or other third party material in this article are included in the article's Creative Commons licence, unless indicated otherwise in a credit line to the material. If material is not included in the article's Creative Commons licence and your intended use is not permitted by statutory regulation or exceeds the permitted use, you will need to obtain permission directly from the copyright holder. To view a copy of this licence, visit http://creativecommons.org/licenses/by$\mathrm{nc} / 4.0 /$.

\section{REFERENCES}

1. Bray F, Ferlay J, Soerjomataram I, Siegel RL, Torre LA, Jemal A. Global cancer statistics 2018: GLOBOCAN estimates of incidence and mortality worldwide for 36 cancers in 185 countries. CA Cancer J Clin. 2018;68:394-424. 
2. Siegel RL, Miller KD, Jemal A. Cancer statistics, 2019. CA Cancer J Clin. 2019;69:7-34.

3. Surveillance, Epidemiology and End Results Program. SEER Explorer. https://seer.cancer.gov/ explorer/application.php. Accessed 28 Jan 2020.

4. Chen Z, Ren Y, Du XL, et al. Incidence and survival differences in esophageal cancer among ethnic groups in the United States. Oncotarget. 2017;8: 47037-51.

5. National Comprehensive Cancer Network. Clinical practice guidelines in oncology: gastric cancer. Version 1. https://www.nccn.org/professionals/ physician_gls/pdf/gastric.pdf. Accessed 30 Mar 2020.

6. National Comprehensive Cancer Network. Clinical practice guidelines in oncology: esophageal and esophagogastric junction cancers. Version 1 . https://www.nccn.org/professionals/physician_gls/ pdf/esophageal.pdf. Accessed 30 Mar 2020.

7. Kim GM, Jeung HC, Rha SY, et al. A randomized phase II trial of S-1-oxaliplatin versus capecitabineoxaliplatin in advanced gastric cancer. Eur J Cancer. 2012;48:518-26.

8. Kang YK, Kang WK, Shin DB, et al. Capecitabine/cisplatin versus 5-fluorouracil/cisplatin as first-line therapy in patients with advanced gastric cancer: a randomised phase III noninferiority trial. Ann Oncol. 2009;20:666-73.

9. Al-Batran SE, Hartmann JT, Probst S, et al. Phase III trial in metastatic gastroesophageal adenocarcinoma with fluorouracil, leucovorin plus either oxaliplatin or cisplatin: a study of the Arbeitsgemeinschaft Internistische Onkologie. J Clin Oncol. 2008;26:1435-42.

10. Bouché $\mathrm{O}$, Raoul JL, Bonnetain F, et al. Randomized multicenter phase II trial of a biweekly regimen of fluorouracil and leucovorin (LV5FU2), LV5FU2 plus cisplatin, or LV5FU2 plus irinotecan in patients with previously untreated metastatic gastric cancer: a Federation Francophone de Cancerologie Digestive Group Study-FFCD 9803. J Clin Oncol. 2004;22:4319-28.

11. Lorenzen S, Schuster T, Porschen R, et al. Cetuximab plus cisplatin-5-fluorouracil versus cisplatin-5fluorouracil alone in first-line metastatic squamous cell carcinoma of the esophagus: a randomized phase II study of the Arbeitsgemeinschaft Internistische Onkologie. Ann Oncol. 2009;20: 1667-73.

12. Enzinger PC, Burtness BA, Niedzwiecki D, et al. CALGB 80403 (Alliance)/E1206: a randomized phase II study of three chemotherapy regimens plus cetuximab in metastatic esophageal and gastroesophageal junction cancers. J Clin Oncol. 2016;34: 2736-42.

13. Cancer Genome Atlas Research Network, Analysis Working Group: Asan University, BC Cancer Agency, et al. Integrated genomic characterization of oesophageal carcinoma. Nature. 2017;541: 169-75.

14. Flatiron Health. Flatiron Health Electronic Health Record database. https://flatiron.com/about-us/. Accessed 28 Jan 2020

15. Bang YJ, Van Cutsem E, Feyereislova A, et al. Trastuzumab in combination with chemotherapy versus chemotherapy alone for treatment of HER2positive advanced gastric or gastro-oesophageal junction cancer (ToGA): a phase 3, open-label, randomised controlled trial. Lancet. 2010;376: 687-97.

16. Arnold M, Soerjomataram I, Ferlay J, Forman D. Global incidence of oesophageal cancer by histological subtype in 2012. Gut. 2015;64:381-7.

17. Cook MB, Chow WH, Devesa SS. Oesophageal cancer incidence in the United States by race, sex, and histologic type, 1977-2005. Br J Cancer. 2009;101:855-9.

18. El-Serag H. Role of obesity in GORD-related disorders. Gut. 2008;57:281-4.

19. Barzi A, Hess LM, Zhu YE, et al. Real-world outcomes and factors associated with the second-line treatment of patients with gastric, gastroesophageal junction, or esophageal adenocarcinoma. Cancer Control. 2019;26:1-8.

20. Chau I, Norman AR, Cunningham D, et al. The impact of primary tumour origins in patients with advanced oesophageal, oesophago-gastric junction and gastric adenocarcinoma-individual patient data from 1775 patients in four randomised controlled trials. Ann Oncol. 2009;20:885-91.

21. Guimbaud R, Louvet C, Ries P, et al. Prospective, randomized, multicenter, phase III study of fluorouracil, leucovorin, and irinotecan versus epirubicin, cisplatin, and capecitabine in advanced gastric adenocarcinoma: a French intergroup (Fédération Francophone de Cancérologie Digestive, Fédération Nationale des Centres de Lutte Contre le Cancer, and Groupe Coopérateur Multidisciplinaire en Oncologie) study. J Clin Oncol. 2014;32:3520-6.

22. Shen L, Li J, Xu J, et al. Bevacizumab plus capecitabine and cisplatin in Chinese patients with inoperable locally advanced or metastatic gastric or gastroesophageal junction cancer: randomized, 
double-blind, phase III study (AVATAR study). Gastric Cancer. 2015;18:168-76.

23. Waddell T, Chau I, Cunningham D, et al. Epirubicin, oxaliplatin, and capecitabine with or without panitumumab for patients with previously untreated advanced oesophagogastric cancer (REAL3): a randomised, open-label phase 3 trial. Lancet Oncol. 2013;14:481-9.

24. Yamada Y, Higuchi K, Nishikawa K, et al. Phase III study comparing oxaliplatin plus $\mathrm{S}-1$ with cisplatin plus S-1 in chemotherapy-naive patients with advanced gastric cancer. Ann Oncol. 2015;26: 141-8.
25. Howlader N, Noone AM, Krapcho M, et al. SEER Cancer Statistics Review, 1975-2014. https://seer. cancer.gov/csr/1975_2014/. Accessed 12 Jan 2020.

26. Rizvi NA, Hellmann MD, Snyder A, et al. Cancer immunology. Mutational landscape determines sensitivity to PD-1 blockade in non-small cell lung cancer. Science. 2015;348:124-8.

27. Snyder A, Makarov V, Merghoub T, et al. Genetic basis for clinical response to CTLA-4 blockade in melanoma. N Engl J Med. 2014;371:2189-99.

28. Mahajan R. Real world data: additional source for making clinical decisions. Int J Appl Basic Med Res. 2015;5:82. 